\title{
Recent issues related to pragmatic lifestyles in Viet Nam
}

\author{
Phu Hop Mai ${ }^{1,2, *}$, JunWu Yang ${ }^{1}$ \\ ${ }^{1}$ College of public management, Hunan Normal University, Changsha, China \\ ${ }^{2}$ School of Political Science, Can Tho University, VietNam
}

\section{Email address:}

mphop@ctdu.edu.vn (P. Mai), yangjwyf@yahoo.com.cn (J. Yang)

\section{To cite this article:}

Phu Hop Mai, JunWu Yang. Recent Issues Related to Pragmatic Lifestyles in Viet Nam. Humanities and Social Sciences. Vol. 1, No. 2, 2013, pp. 70-77. doi: 10.11648/j.hss.20130102.11

\begin{abstract}
In Vietnam, when the social develops then the living is raised higher, and the influence of foreign culture, especially Western culture and American culture, become the most powerful and fastest. The transformation of values is happening on many areas of social life that associated with the institutions about economic, political, social and cultural. So, individualism and active lifestyle is more enhanced. However, the pragmatic lifestyle, the emotionless lifestyle and the epicurean lifestyle are also developed and its consequences have also been influenced greatly with respect to social. The article provides positive and negative expressions of pragmatic lifestyles, thus making comments on measures to reduce the restraints of these lifestyles.
\end{abstract}

Keywords: Viet Nam, Pragmatic Lifestyles, Hedonist Lifestyle

\section{Introduction}

Pragmatism, which is a non-Marxist phylosophy, becomes a "semi-official" theory of American lifestyle and has made tremendous impacts on different aspects of the social life of America for decades. It is reflected in politics, society, culture and even morality, lifestyles and education. Researchers believe that pragmatism is an inevitable characteristic born from socio-economic conditions and features of American culture, as well as American ways of thinking. Therefore, when American culture and American lifestyle intrude into any country, they bring in contents of pragmatism with different modifications. Pragmatism, during his development process, has made tremendous effects on many countries in the world, such as Germany, Italy, China, Japan, Viet Nam...

As for Viet Nam, when we study the effects of pragmatism, we should look at two different periods: The pre-1975 and post-1975 periods, which reflect different levels and characteristics. Before 1975, pragmatism was taught in universities in the South of Viet Nam, that is the reason why pragmatism made tremendous impacts on intelligentsia. In addition to that, the impetuous intrusion of American lifestyles into different fields of the society, which was referred to as "hasty lifestyle", "pressing lifestyle", also contributed their parts to the process.

However, when the country was liberated, pragmatism was no longer taught, but its effects still remained and these effects were reflected in cultural products (films, music, education and other fields, which could not be easily recognized). We called it a spontaneous process, (meaning that pragmatism was transformed into different forms in culture). Therefore, looking for the effects of pragmatism is to find their reflections in culture, education, lifestyles, and ways of thinking, economy, and politics.

The influences of pragmatism would be explained in different viewpoints, but we believe that it depends on the effects of market-based economy, as well as the integration process and globalization.

The market-based economy was formed in Viet Nam and it has initially gained dynamic growth recently. The living standards of the citizens are greatly improved. The processes of globalization, international integration have brought about new and modern things associated with many countries in the world. In the same time, it has created bad changes in the awareness of some parts of the citizens concerning traditional values, individual and community-based lifestyles. The most remarkable feature is the trend to look down on, even refuse traditional cultural values of the country and overreacts with foreign values, which would be perceived as "new" and modern. To evaluate these realities over the past years, the Resolution of the Central Party Committee in Plenum V (8th Tenure) stated: "The bad practices cult of foreign elements, looking down on traditional cultural values, running after pragmatic, 
selfish personal lifestyle... are very harmful to the good traditions and customs of the country" [1]. It is not a rare reality when someone over-appreciates the values of money and makes harmful impacts on the good values of families and the relations between teachers-students, colleagues and comrades. Not only the relations between people in the market, but also relations between people of the families are badly damaged by the strength of the money. Due to the seduction of money, people are willing to let their relatives sell their honours and support social evils. Due to the seduction of money, children could torture their parents, brothers are apart and husbands and wife get divorced... The relations of the families are totally upside-down. The chaos found in family relations creates favourable conditions for the development of evil and dishonest features.

In schools, people, especially students, begin to pay so much attention to individual benefits and want to choose professions that could make them become rich and earn the power. When they graduate from schools, most of them do not want to work for authorities of the Party, organizations or education system... Bad habits of students could be named as cheating in the exams, gambling, careless sexual relations, superstitions, being drunken, no disciplines, using drugs, keen on pornographic products, worshipping the practical lifestyles... Based on this reality, we could find out that moral issues of students need to be seriously studied and solved.

There are strange ways of living and lifestyles that go against good traditions and customs of the country. Parts of the citizens and social classes are willing to damage good and traditional moral values when they look for their individual benefits. Corruption, smuggling, illegal enriching efforts and other social evils are more and more popular. Especially, "a not small number of officials, party members are losing their belief, lacking their vigilance, willpower decrease, lacking of disciplines, determination and become depraved in morality and their lifestyles"[1]. Reality shows that, in recent years, the cases of smuggling, drug dealing and making fake goods are increasing. A number of young people tend to follow pragmatic and careless lifestyles, paying so much attention to the values of money and turning their back on values of traditional culture and morality. Despite of the peace-loving traditions of Vietnamese peoples, parts of the citizens, especially young people, teenagers have committed their lives with violence. During the transformation process into market-based economy, Vietnam has to deal with the increasing and serious criminal situation. Many dangerous crimes appears, such as terrorism, blackmail, children kidnapping, women trafficking, explosion trafficking, drug dealing, hired killing, sex brokerage, drug use. We also witness the increasing number of cases of women and children committing crimes".

\section{Raising of Individualism and the Active Lifestyle of Vietnamese People}

Vietnamese people nowadays are more practical in choosing the professions and knowledge. In other words, people are more aware of the purposes in actions and ways of thinking. Therefore, Vietnamese people could take full advantages of fruitful results brought about by the globalization process. Thanks to the globalization process, they could maximize the position of the developing country to "take shortcuts" to gain achievements in techniques and technologies; creating favourable conditions for the development of the country, thus make strong impacts on cultural development; approaching enormous knowledge ocean of the human being; the lifestyles of many Vietnamese people in general and Vietnamese students in particular have changed so much, thus transforming their inactive, close lifestyles into more open, active and modern lifestyles.

One of the most remarkable impacts of globalization, which focuses on individualism, is the reflection of moral values in the viewpoints of individuals.

Individualism is now regarded as the indicator for activities, meaning that the morality or immorality of the activities depends partly on the spiritual heritages passed over by previous generations, and it remains greatly dependent on the individuals, which contributes to the formulation of the new generations. The individual-based moral viewpoints are separated with traditional moral viewpoints, which are considered to be not suitable with the new era due to the changes of objective conditions. Being self-aware of themselves and less dependent on public opinions make individuals active and quickly get access to new things in science, techniques and technologies, as well as paying much attention to the study of knowledge, thus best serving the professions.

Actually, leaving behind our steps the outdated heritages of the past is not easy, because they are rooted in the mindset of the communities over a long period of time. And reality also shows that, what is called "radition" would remain stable and be passed over from generations to generations, so it exists in the ways of thinking, habits, customs of the people, even their foundations have been changed. But the globalization process is a catalyst, a lever, as well as requirements for peacefully leaving behind the outdated past, because they understand that "traditions of the dead generations are putting the weight of the mountains into the minds of living people" [2]. It is the role of young and knowledgeable people, who grow up in new environments, to comprehensively, clearly leave behind the burdens of the past with no excuse and nostalgia. Because they are the ones whose connections with the past are not strong enough, they could easily leave behind outdated values of the past and acquire new things, accept new values in the constantly active environment.

The eagerness for learning, the capability to overcome difficulties to study well for a new, bright future help many students achieve good academic results. Many Vietnamese 
students have won high prizes in International and Olympic contests. They not only prove their capabilities, but also help to strengthen the status of Viet Nam in the eyes of international friends. Especially, during the process of globalization, Vietnamese students are more and more active and they could easily adapt with general trends of the world. Thanks to good adaptability and sensitivity, students could master knowledge and skills suitable with the era of information technologies. In addition to that, globalization also creates similarities between moral viewpoints and code of conducts of a community (Vietnamese students), reflected by international moral viewpoints and code of conducts. As they are young, knowledgeable, capable of learning new things, well-equipped with skills related to foreign languages and information technologies, with the support of modern facilities, as well as the openness and diversification of international exchanges, students could easily adapt with the new flows of the integration process. It helps to bridge the gap between moral viewpoints, which would be done by a spirit of openness and sympathies. In addition to their own identities, Vietnamese students also absorb new features of the world, which help to formulate general moral viewpoints of human being and in the same time they can maintain good traditions of our peoples in general and Vietnamese students in particular.

\section{Pragmatic Lifestyle and Indifference of Vietnamese People}

What is worth paying attention to is the above-mentioned positive impacts themselves, which are over-appreciated by the young people, leading to the fact that they become misunderstood and become very negative. This is the place where the conflicts between the thoughts and the lifestyles of people are exposed and we could witness the two-side effects of one element.

The most remarkable negative impact is the practical way of thinking concerning behaviours, in which material values are more appreciated than spiritual values by parts of young people. Democracy, the advancements of information technologies and the improvement of knowledge help to increase personal awareness. They are aware of themselves and they would like to express their individual roles. However, sometimes individualism surpasses collective values and they attach higher values to individualism, in comparison with others. The typical sample of this situation is the formulation of indifference behaviours extended to other peoples. They only sacrifice or care for others if these behaviours bring them economic returns, rather than emotions and sharing. Sacrifice and care extended to others will only occur if these behaviours bring about benefits to them. This situation is clearly mentioned in the study of Ms. Nguyen Thi Anh Hong (lecturer of Education Faculty, University of Social Sciences and Humanities - The National University of Ho Chi Minh city), who have carried out social surveys on the lifestyles of students recently.
Students are randomly chosen from 3 member univeristy (University of Natural Sciences, University of Social Sciences and Humanities, University of Technologies), in which the researchers use Factor Analysis and discriminatory analysis to study the ways the students choose their basic activities. And the researchers discover 3 basics lifestyles of students in Ho Chi Minh city at the moment. In which, $60 \%$ of the students have close lifestyles and rarely participate in social activities!. They still pay attention to their studies and usually meet, look after friends and relatives, but the scope is very limited. In addition to that, they watch television, read newspapers. But they rarely participate in social, political and collective activities. This is a lifestyle lacking dynamism, activeness and integration into social lives. They are often indifferent with the current events happening around them [3].

It is the responsibilities of individualism and negative impacts of pragmatic lifestyles that create "the disease of indifference". Those who are infected with "the disease" will feel indifferent with the pains of others, as well as the social evils occurring in front of them. People become emotionless with the lives of others, they only care for what could bring them benefits, so that "each person lives his/ her own life". Elderly people often said "The pain of a horse makes the whole group of horse stop eating" or "You should care for others as well as the ways you care for yourself". These viewpoints become very popular and they are regarded as the moralities and good traditions of Vietnamese people, which have always been maintained and promoted. However, in addition to those who know how to share, sympathize with others and care for others, there are also people who are very selfish, indifferent, apathetic and they only care for themselves.

The matter of indifference in the society is a puzzle for educators, parents and responsible persons. The "indifference disease" creates tremendous impacts on the society. Nowadays, young people would have more opportunities to study, learn knowledge than previous generations. Many public and private schools are open to help young people become knowledgeable and moral, serving the society and developing the country into a knowledge-based, morality-based society, keeping pace with the growth of other countries in the world. We are very painful to witness emotionless and immoral acts of young people in the media or newspapers. For example, it is now really popular to see female students fight with one another, strip off and tear the clothes of their friends, or students beat their teachers so badly that the teachers have to be hospitalized. What is worth being condemned is the fact that most of young people stay indifferent and they pretend not to see anything at all. Instead of stopping the cases, some others do the cheering and support these immoral and cultureless acts.

Recently, internet users are very shocked with the hooligan acts of groups of female students in Bac Giang, Bac Ninh, Quang Ninh, Hai Phong, Ha Noi..., in which the victims are beaten, their clothes are torn and their hair is cut. 
"The recorder of these images is a male student. Together with the abuse acts of the girls, the male student is very excited in cheering up these acts: "Strip off the clothes, strip off, strip off..." Moreover, many people are also shocked with the indifference of people born in the 1980s, 1990s. Some of them are very wealthy but they are not willing to help people in serious needs and difficulties. Many young people drive away and sneer at beggars. Some people refuse to help those suffering from accidents, some keep going away instead of helping these people and others even steal the money of those suffering from accidents. These acts make other citizens very angry but they are not seriously dealt with. That is the reason why the Ministry of Transportation and Communication seek the comments of public opinions, so that the fines could be increased for acts of making individual benefits out of people suffering from accidents.

Recently, the criminals committing the crime of killings become younger and younger. Many criminals were born in 1980s, 1990s. For example, the public are very concerned about the robbery and killings happened in Ngoc Bich jewelry (San street, Luc Nam district, Bac Giang province [4]). "The emotionless guy", who killed 3 persons, was Le Van Luyen, who was just 17 years old. Some people say: "The criminal act of Le Van Luyen is the most serious, barbarous, brutal and emotionless act ever seen". In addition to that, Ho Nhat Linh, 18, who live in Bo Trach, Quang Binh province [5] stabbed the knife 95 times in a woman, who was pregnant for 8 months, killed her and then threw her body into the canal. The murder case concerning the recent killing of 5 aloe wood collectors [6] raises the fear of indifference...

After many painful cases occurring currently, there appears a matter which becomes worse and worse: Are Vietnamese people more emotionless? This phenomenon is reflected by the indifference, "each family would care for its own affairs", or figuratively speaking, people are acting like "robots" and they become brutal, emotionless.

The phenomenon of being emotionless is not a crime, but it is a very short way to crime. Being emotionless and senseless acts will lead to crime and painfulness, which will lead to the incapability of controlling yourself... What is worth paying attention to is the fact that it is not the story of an individual, it becomes the "feature" of a modern society. Ky Duyen [7] has mentioned that "The ever-increasing insensitiveness would occur in all fields and many social classes, leading to painful catastrophe of morality. Individually speaking, insensitiveness is reflected in the selfishness, coldness and narrow-mindedness of a person extended to miseries of other people, as well as other matters requiring the support and assistance of the communities. Collectively speaking, the phenomenon is a bad situation occurring in the body of "the society".

Abandoning people suffering from accidents, even trying to rob them. And terrible crimes are resulted from very petty reasons. The moral values connecting relations regarded as the fundamental foundations of the society, such as parents-children, teachers-students... are distressed. The bribery, corruptions happen widely in different levels... These are different reflections of indifference.

There is a paradox that most of Vietnamese people recognize: Nowadays, the material development of the society is widely known. The indicators related to living standards, economy, cultural enjoyment, education... are greatly improved, in comparison with other previous decades. The quality of life is also increased, people become richer, the cultural attainment is improved, and the society is more civilized... But as the society becomes more civilized, do people become more emotionless? In addition to that, young people, who are young masters of the country, are most infected by "the disease of indifference". Many people are shocked with the practical lifestyles of many young people, who always run after the values of money and contemporary values.

The impacts of "this disease" are very serious. People who are emotionless with the affairs of the country, of the people would not be able to control themselves, master their own countries, the people... "The "development" of indifference would lead to the fact that Vietnam has to deal with a tragedy occurring in the souls of the people "[8].

It is a very important matter: Why indifference becomes more and more popular? What are the reasons lead to this situation? Many people believe that this is resulted from pragmatic lifestyles and impacts of market-based economy.

People run after the material values and forget to strengthen the spiritual values. The community spirit, the mutual help, which are good traditions of Vietnamese people, are no longer familiar and they would be replaced by benefit-based considerations, in which the support and care would only be extended if benefits are found. "The snatches of the market-based economy would easily destroy the culture and morality in an easier way, which could be reflected in many other countries. This is the reality that we have to recognize, in which a culture with so many limitations would make breakages of values happen more easily and bring about many consequences" [9]. According to Ms. Ly Thi Mai, consultant of Ho Chi Minh City Consultancy Centre for Marriage and Family Affairs, "Young people only "know about themselves", and the situation becomes more popular, that is the reason why indifference really intrude and become rooted in the mindset of young people nowadays!". Moreover, it is the responsibility of indifference, which is resulted from selfish, pragmatic lifestyles that make people feel that their lives are boring, meaningless and monotonous. Consequently, moral emotions are restricted, even annulled.

However, some people believe that the matter is not simply located in market-based economy. Reality shows that some countries, market-based economies could gain benefits since their early ages, but if the societies are stable, how could these painful acts happen?

The reasons come from deadly: lacuna errors of the educational system, which is now operated in the schools and families. These places bring about many errors. 
Families are the "cells", "fundamental elements" of the society. According to psychological consultant Trieu Hong Nhu from Ha Noi Psychological Consultancy Centre, "the reactions, the behaviours of young people are partly resulted from factors of the society and partly influences of the families. Sometimes, it is the responsibility of the lifestyles of young people... The habits to narrow the communication and the wishes to contact virtual people in game onlines; the popular appearances of violence in video games, television, manga and other favourite hobbies of young people would lead to the ignorance and apathy extended to affairs happening somewhere around - This is an unavoidable consequence"[10].

While providing the proverb: "You should teach your child when he/she was young", Vietnamese people are well-known for children-teaching experiences. But nowadays many families do not regard this as an important issue and they do not care how to teach their children the ways to sympathize, love and forgive the others, because the parents themselves are not role models for children in terms of morality, lifestyles and they even do not pay attention to teach their children. Nowadays, how many parents would spend time teaching their children how to behave well, self-respect and respect others, teach their children to be tolerant, generous, altruistic and teach them about other moral standards that people should follow and respect as a human being should do?.

In addition to that, parents pay to much attention to earn money and they forget to teach their children. They care so much about their children and they are willing to unconditionally satisfy the unreasonable requirements of their children. But only few parents know what their children - their princesses and princes will do when they "have" money in their hands. Many "good kids" will burn their money in bars, discotheques with unhealthy habits. In addition to that, the parents do not teach their children how to share, pay attention and live responsibly together with relatives and friends. Children only know how to "receive, they do not know how to "give away", and they will be very poor in terms of emotions and become indifferent with the pains of others.

Schools would be the places to train the "talents" of the country and bring about people who have the talents and morality. These people would know how to care for other and serve the country. But nowadays, in some schools, they only pay attention to cram the knowledge and the studies become very practical in the way that help students cope with the exams, leading to the fact that subjects of studies related to the studies would be paid attention to, and other morality matters are forgotten. Many schools even teach citizenship education for form's sake. Nowadays, schools are no longer ideal places to help students "learn moral issues first and then study educational matters later". The relations between teachers and students become vacillate, because of the impacts of the environment and the moral reduction of many female and male teachers. In addition to that, some schools are incapable of - or inattentive in providing their students backgrounds of knowledge and compassion, which will help to stop and prevent indifference. Schools only teach their children about good things and they forget-what is considered to be a weakness-that they should teach the children hate the bad things.

It can be said that the reasons should be the deterioration of social morality and the good values are affected. Precisely, it is the consequence of a society when the belief is very fragile, pragmatism is popular and selfishness is very widespread. Bribery, corruption become very popular. Moreover, indifference is the consequence of pragmatic lifestyles, which is deeply rooted in the society. Good morality values, love, care, magnanimity, sacrifice... are recently replaced by materialism, utilitarianism and individualism. People are emotionless with the pains of their human being partners. In addition to that, the increase of social unfairness, bureaucracy, corruption and the "envelope" lifestyles make adults no longer moral models for young children, and the moral values are decreased.

According to Ms. Trish Summerfielf, Director of the "Living Values: An Educational Program", who have lived in Viet Nam for the past 10 years, market-based economy have contributed to the deterioration of culture, as well as the formulation of indifference. This is the responsibility of parents who do not care much about their children, materialism is over appreciated and the abuse of diploma and certificate values, the educational system is not scientific and objective [11]...

Vietnam is aware of the consequences of this serious disease. People who are emotionless with the affairs of the country and other people would not be able to control themselves, help their people and develop the country. As the indifference phenomenon is more serious, Vietnam could witness the fact that an unstable society would appear in the minds of the people.

So, what should we do to get rid of the disease?. The "most important" and indispensable medicine is the formulation of serious fines, so that the order could be restored. When the legal punishments and fines are strong enough, people would be aware that, emotionless acts would not only go against moral values and they may violate legal regulations and they would suffer from serious punishments. Do not rescue people suffering from accidents when you see them, it is an illegal act. Stealing things from people in accidents is illegal. Using violent acts to kill, torture anyone would be heavily punished... In a society of sound disciplines, people will act in pursuance with relevant standards.

As for corruption, the most striking and high-level reflection of indifference, it would be a very effective medicine. It would be indispensable vaccine in the intense "treatment". When punishments and legal regulations become serious, the society would become more transparent and the "vitamin" for corruption would be reduced quickly.

To achieve these expectations results, we need the joint efforts of every person. The State and the people should think, work out and provide solutions, help each other and 
recover the consequences.

\section{Hedonist Lifestyle of the Vietnamese People}

The other negative impact is the fact that, together with the lifestyles and industrial products imported from foreign countries, many young people leave behind good traditional and moral values, which are still suitable with the modern era. In an open economy and society, people only like to Hedonist lifestyle, play around and they are vulnerable to social evils, leading to the changes in terms of moral values and lifestyles. The moral values of many young people are going against standards and especially, many people believe that morality values and individual benefits could be homogeneous. Concerning this matter, the results of a statistical survey are provided by Ms. Nguyen Thi Anh Hong, in which $10 \%$ of students pay attention to enjoyment activities, in which some activities are useless and they pay less attention to their studies, the enrichment of their knowledge, as well as the improvement of their characteristics. "I only like telephones of new generations...", "The Korean film is showing the episode....", "Fashionable things are sold in...". This is what these young people pay attention to. However, they are very active and enthusiastic in playing around, enjoying the hobbies for young people, expressing the "fashionable" ways of living. But sometimes these "enjoyable" activities make them forget the way back home.

Many people believe that they are deserved to enjoy the hobbies, personal satisfaction and they only want to make themselves happy. They think that they were born in the families with good economic conditions and it would be the honour, happiness for the families to see them study in the universities, and that's the reason why they think they could do whatever they want. They burn money, time and health in useless games, bad recreational activities, their hobbies and later they have to suffer from the consequences of what they believe they deserve to get. But the consequences they get are the facts that they lost themselves, their families, friends, cousins are affected and involved, and finally they have to get the punishment for these acts.

The material lifestyle is not only popular with young people, they are widely known in Vietnamese society nowadays. The pragmatic lifestyle and Hedonist lifestyle, "luxurious and crazy shopping" is so familiar. They enthusiastically and happily care for their appearances and enjoyment, and this phenomenon becomes popular. Some people pay attention to fashionable outfits, ride expensive motorbike and use high-end products. The saying: "Ride expensive cars-make contributions to bars-sing in mobile phones" becomes standards and mottos for young people nowadays. Illegal racing, careless sexual relations and doing harm to other people just for fun - Their lives are full of enjoyment and no effort is seen to improve themselves to serve the country. Young people only pay attention to material lifestyles as young people in Western countries.

They are very practical, and when they have to face difficulties, problems in their lives, event this is small challenge, failures in the careers and problems with the love affairs, as well as hitches in the relations with their families, their friends, they lost the directions. Instead of trying their best to overcome these problems, they are discouraged and find the solutions in drugs, sex, gangsters and death...They try to escape reality by finding enjoyment in unwholesome services related to karaoke, massage, billards, café or wine. These are what young people try to do, and they sometimes use drugs to forget reality. In addition to the fact that they would like to get rid of difficulties of reality, they want to become "famous", to prove themselves. They want to prove that they are not living with unrealistic thoughts, which could not bring benefits to them. They think that it is very obvious to have a practical lifestyle, because the calls for pragmatism are so popular, the materials are very abundant and the ideology is somewhere very far away from reality.

As for successful young people, only a few of them devote themselves to serve the country, and they pay attention to more practical things like their personal successes, as well as what are related to their current lives, such as diplomas, knowledge, love, assets, friends and enjoyment. They have practical and wise eyes, but they are egoistic. It is the ideology for them to get quick promotion and ensure their lives with stable jobs.

They do not care much about social and political issues. "It is an alarming fact for leaders, because Vietnamese young generations do not care much about the events, incidents occurring in the governments, meetings of National Assembly delegates and Party meetings, elections... Even though these important meetings are live broadcast, but most of young people do not care. They only enjoy Korean, Japanese and Taiwanese films... They do not even care who will be the President of the country in this tenure..." [12] . Therefor, there is a movement that young people choose aimless lifestyles and do not care about orientations or directions. Many young people deliver negative comments, which refuse the role and values of organizations in their lives. Instead, they enthusiastically join in groups of people who like enjoyment. It seems that they are very busy with their studies and their own business, and they do not have time and determination for what they think is not necessary. Politics was a hot issue for many previous young generations in the past, but it is now very strange for young people. For decades, we can not see any thoughtful letters, proposals, meetings of young people to protest social evils, to fight for humane ideology and proposal reforms. Sometimes, they are riotous, but these riots only happen at night: café, karaoke, beers, illegal racing, drugs... "Culture of speeds" is the "weapon" of night racers.

Is this the fact that we have witnessed the generations of pragmatism, generations of ignorance and generations of violence? Many Vietnamese people raise questions: How much hope should we spend on young people who only pay attention to speeds at night, use drugs in luxurious hotels, go 
out with groups screaming after a winning match...? Should we entrust these guys with the mission to transform Vietnam into an ideal society, a better place to live?

In the society, the phenomenon of pre-marriage sex, one-night relation, cohabitation is increasing. According to survey of VnExpress, with the participation of 13,500 persons answering the question "Should we try cohabitation ?". 7,600 persons, accounting for 56\% of participants, agree with the proposal of cohabitation, only $36 \%$ disagree with this idea. Other people have different opinions. The survey reflects a real trend in everyday life [13].

According to a survey carried out by Ho Chi Minh City Institute of Social Science and the Central Committee of Ho Chi Minh Communist Youth Union and done in 5 universities in Ho Chi Minh city and 3 universities in Ha Noi, only $30 \%$ of participants oppose the pre-marital sex. The others accept, considering it as a normal phenomenon. Some think that it is not good, but do not oppose against this[14].

In Vietnam Labour newspaper dated $26^{\text {th }}$ March 2011, author The Uyen stated that sexual relations is a trend to "express themselves" of young people. According to Doctor of Psychology Huynh Van Son, Ho Chi Minh City University of Pedagogy, pre-marital sex of young people is the phenomenon influenced by Western and by the bohemian lifestyle, which contribute to the deterioration of Oriental people, those who always respect family values, moral values; men and women should not be flippant; girls should be modest and gentle... And the consequences of this situation are the phenomenon of abortion and they are very stressful now. According to Professor Doctor Nguyen Thi Ngoc Phuong, Director of Tu Du Maternity Hospital in Ho Chi Minh city, the abortion rate is very alarming. Annually, there are 700,000 women in Viet Nam experiencing abortion. In Ho Chi Minh City, whose population is around 7 millions, the annual maternity cases are about 100,000 , but the abortion cases are somewhat similar. In Tu Du Maternity Hospital, the annual maternity cases are about 45,000 , but the abortion cases are 30,000. The number of abortion cases of the whole country is $1.2-1.6$ millions per year. About 5\% of women gave birth to their children at the age of 18 and $15 \%$ at the age of 20 [15]. Teenagers (from $10-17$ years old) in Viet Nam account for $31 \%$ of the population $(23.8$ millions). According to the statistics of Family Planning Association, the number of abortion cases of the whole country is 1.2 - 1.6 millions per year [16], in which $20 \%$ are at the age of teenagers. The national report on teenagers and young people of Viet Nam shows that $7.6 \%$ people of these ages will experience pre-marital sex. With this record number, Viet Nam ranks first in South East Asia and $5^{\text {th }}$ in the world concerning the number of abortion cases of people at the ages of teenagers.

The consequences of these matters are the facts that $1.16 \%$ of those infected with sexually transmitted diseases (gonorrhoea in this case) are children below 15 years old and this number is $1.5 \%$ concerning other venereal diseases, which are the causes of infertility. By $17^{\text {th }}$ January 2013, the number of $\mathrm{HIV}$-infected people who are still alive are 209.372 cases, the number of AIDS patients is 53.834cases. The number of people die of HIV is 54.200cases [17].

Many young people choose bohemian lifestyle, with distracted concepts. For them, pre-marital sex is "a normal feature" of a "modern and civilized lifestyle". Therefore, they carelessly "make their choices" despites of consequences. The reasons for this matter are as follows:

- Lack of care and attention from the families. Parents focus too much on their own business and do not pay much attention to their children. Or there are parents who only care about educational achievements of their children and do not pay attention to the emotions and feelings of their children. Many parents believe that sexual education is somewhat "the introduction for bad behaviours". They only try to satisfy the material needs of their children and they think that it is enough. For children, they are very eager about the topics of sex, love. Some other children are desperate because of the breakages of the families, so that they play truant and they are easily attracted by bad habits and social evils.

- The school system is weak in their education topics related to psychology, sexual health and preventive measures. Teachers are partly not given standard trainings to deliver educational sessions on sexual health; moreover, many of them believe that this is a private, not serious issue and they avoid this issue.

- Due to economic and cultural integration, the society is affected by bad cultural habits and good traditional values are damaged. Moral standards are being lost and the lifestyles are pragmatic, some people are jostling and making everything possible to earn economic benefits. The ever-increasing appearances of hotels, bars, discotheque support dissipated lifestyles. Young people are attracted by unhelpful pleasures, which could result in terrible results. Abortion is somewhat nearly a normal phenomenon of the society. The availability of abortion services, which are very widespread, convenient and cheap, with simple procedures, makes women misunderstand that this is a preventive measure and consider it as a proof for ever-increasing bad sex behaviours.

\section{Conclusion}

When Viet Nam opens its door and gets contacts with the outside world, different, foreign culture and values will flow in. The matter is the fact that we couldn't and are unable to stop these cultures and values, we have to enable every member of the social especially young people, with the capabilities to become resistant with the bad effects of the cultures and lifestyles. Don't make young people worse in moral values. To so so, we should join hands to enable young people to avoid traps of the society, make them live better and contribute their parts to the construction of the country. Therefore, as we mentioned above, Vietnamese laws should be forcible, deterrent enough and the education system should comprehensively enhance moral and sex education. 


\section{References}

[1] Đảng Cộng Sản Việt Nam. 1998. Văn kiện Hội nghị lần thứ V - BCH TW khóa VIII. Nxb, Chính trị Quốc gia, Hà Nội, pp 46.

[2] Marx - Anghen toàn tập, tập 8, 1995. Nxb Chính trị Quốc gia, Hà Nội, pp 145.

[3] VNN. 2003. Thấy gì qua lối sống sinh viên thời nay. http://chuyentrang.tuoitre.vn/Vieclam/Index.aspx?ArticleID $=9947 \&$ ChannelID $=96$.

[4] VnExpress. 2013. Vụ thảm sát tại tiệm vàng Ngọc Bích. http://vnexpress.net/gl/topic/6643/vu-tham-sat-tai-tiem-vang -ngoc-bich/

[5] Minh A. 2013. Những nữ sinh bỗng chốc biến thành sát thủ. http://vietnamnet.vn/vn/xa-hoi/75368/nhung-nu-sinh-bong-c hoc-bien-thanh--sat-thu-.html

[6] Tin tức 24h. 2013. 5 phu trầm bị giết trong rừng. http://hcm.24h.com.vn/5-phu-tram-bi-giet-trong-rung-c46e2 606.html.

[7] Kỳ, D. 2011. Sự vô cảm nhân danh . . . đồng loại. vietnamnet.

[8] Minh, C. 2011. Càng văn minh, càng vô cảm. vietnamnet.

[9] Hà, V. T. 2011. Căn bệnh trầm kha nhất của xã hội đương đại. http://tuanvietnam.vietnamnet.vn/2011-09-15-can-benh-tram -kha-nhat-cua-xa-hoi-duong-dai-

[10] Thông tấn xã Việt Nam. 2013. Giật mình với thú ăn chơi "bầy đàn" của giới trẻ Việt.

[11] Baomoi.com. 2010. Bạo lực, vô cảm giết chết giới trẻ. http://www.baomoi.com/Bao-luc-vo-cam-giet-chet-nguoi-tre /139/4018199.epi.

[12] Nguyễn, P. T. 2012. bài phát biểu Đại hội đại biểu toàn quốc lần thứ X Đoàn TNCS Hồ Chí Minh.

[13] Như, T. 2005. Sống thử - xu hướng trong giới trẻ. http://vnexpress.net/tin-tuc/xa-hoi/song-thu-xu-huong-tronggioi-tre-2027604.html

[14] Thủy, L. 2013. Câu chuyện của những bà mẹ bế con đi học. http://phapluatxahoi.vn/20130310090012205p1001c1049/ca u-chuyen-cua-nhung-ba-me-be-con-di-hoc.htm

[15] Vũ, V. Tr. 2010. Vấn đề đạo đức của giới trẻ ngày nay. http://tgpsaigon.net/baiviet-tintuc/20100916/6685.

[16] Hội Kế hoạch hóa gia đình Việt Nam. 2011. Gần 300 nghìn ca nạo phá thai vị thành niên mối năm.

[17] Bộ Y tế. 1013. Tạp chí thông tin Y dược, Tình hình dịch bệnh tháng 1 năm 2013. 